\title{
Como ler imagens? A lição de Roland Barthes
}

\author{
Rodrigo Fontanari
}

Resumo: Este artigo visa aproximar o conceito de mito, como definido por Roland Barthes em sua obra Mitologias, da noção de studium estabelecida em seu outro livro, A câmara clara, uma vez que essa noção barthesiana acena com a possibilidade de compreensão a partir de uma espécie de remanejamento daquele conceito de mito para o campo do fotográfico. Trabalhamos com a hipótese de que esses operadores barthesianos podem ainda ser úteis para pensar as imagens na contemporaneidade dos estudos de visualidade.

Palavras-chave: imagem; studium; mito; punctum; fotografia; Roland Barthes.

Abstract: How to read images? The Roland Barthes's lesson - This paper aims to bring together the concept of myth as Roland Barthes has defined it in his work Mythologies; as well as the notion of studium established in another of his books, The camera lucida, since this Barthesian notion beckons with the possibility to be understood as a sort of rehandling of this concept of myth to the field of photography. We work with the hypothesis that these Barthes's operators can still be useful in the analysis of images in the contemporary studies of visuality.

Keywords: image; studium; myth; punctum; photography; Roland Barthes.

\section{Notas introdutórias}

Passados pouco mais de trinta anos do acidente de Barthes em $1980^{1}$, o estado de arte de sua obra avolumou-se consideravelmente e nos permite, com o distanciamento do tempo, desconfiar que, ainda que quisesse ser esse "sujeito incerto" e "impuro", em que cada atributo seria combatido pelo seu contrário, como nos fazia saber em

1 Sabe-se, desde a publicação da biografia de Jean-Louis Calvet (1993), que Roland Barthes faleceu em 26 de março de 1980, decorrente das complicações de um atropelamento provocado por uma camionete de lavanderia, na Rue des Écoles, nas imediações do Collège de France, em 25 de fevereiro de 1980. O pensador saía do Collège, depois de ir regrar o tempo de projeção das fotos do Seminário que concluiria o curso A Preparação do Romance, para, então, prosseguir rumo ao encontro com o futuro presidente da república francesa François Mitterand. 
sua conferência inaugural à cadeira de Semiologia Literária no Collège de France, ele teria sido, "surpreendentemente, constante".2

Tanto é que, mesmo o arco de tempo constituído de vinte e três anos entre a publicação francesa de Mitologias, podemos entrever essa "espécie de etnografia da sociedade francesa contemporânea através dos signos que ela emite" (CALVET, 1993, p. 169), e A câmara clara, uma meditação a respeito do signo fotográfico e a sua experiência profunda do tempo. Podemos entrever, entre essas obras barthesianas, uma coerência no que se refere à crítica da imagem fotográfica. Como semiólogo das mídias que foi $^{3}$, Roland Barthes nos dá, através de seus olhos críticos, uma lição de como avançar numa análise dos textos visuais. Para podermos caminhar nessa direção, façamos uma apresentação desses dois volumes.

\section{De Mitologias}

Mitologias, originalmente, recupera um conjunto expressivo de cinquenta e cinco textos, "pequenas mitologias do mês", escritos entre 1954 e 1956. Os primeiros artigos foram publicados na revista chamada Esprit e, tempo mais tarde, na Les lettres nouvelles, como informa o próprio Barthes na apresentação à primeira edição em 1957. Aliás, em nota para uma reedição desse mesmo volume, em 1970, Barthes (2006b, p. 5) adverte seu leitor de que Mitologias é, ao mesmo tempo, "uma crítica ideológica da linguagem da cultura dita de massa" e, por ter acabado de ler as anotações de Ferdinand de Saussure para o Curso de linguística geral, a "uma primeira desmontagem semiológica dessa linguagem". ${ }^{4}$

Se é bem verdade que, de início, Roland Barthes ainda via o mundo existir para além da linguagem, atento à realidade social, como se espera de um intelectual de esquerda e cultuador de Brecht, é certo que já o via também como linguagem. Neste primeiro Barthes (2006b), é possível entrever uma "Cozinha do sentido", em que o "mito" não tem aí nenhum sentido místico tal qual o "fetiche da mercadoria" adquire em Marx. Mitologias debruça-se sobre a seguinte temática: mascaramento da ideologia pelos códigos das mídias, ou melhor, o repúdio do crítico em relação à maneira como a indústria cultural mascara a realidade, dando por natural aquilo que é historicamente construído. É o que Barthes (ibidem, p. 11) acaba por escrever logo na abertura do livro:

2 Refiro-me, certamente, aos expressivos trabalhos da crítica literária e aos da professora do Programa de Pós-graduação em Comunicação de Semiótica da PUC-SP, Leda Tenório da Motta (2011, p. 32), que, em sua obra Roland Barthes - uma biografia intelectual, vislumbra "um ponto de fuga para todas essas dispersões, ou de um certo centro insuspeito de Barthes, para o qual tudo convergiria, como imperceptivelmente". Esse ponto constitui, segundo Motta (ibidem, 2011), o conceito de neutro. Essa hipótese é também partilhada por Marie Gil (2012).

3 Refiro-me à Sistema da moda (1967) e à A câmara clara (1980)

4 As "mitologias" não cessam com o aparecimento do livro, mas avançam até 1959, com a publicação do último texto intitulado "Os dois salões". As "mitologias" encerram, de fato, no mês de novembro do mesmo ano. Ressaltamos, ainda, que, recentemente na França, foi publicado Mythologies Illustrés, resultado do esforço de Jacqueline Guittard, maître en conférence na Universidade de Picardie-Jules Verne, que leva ao público um trabalho exaustivo em torno das "velhas mitologias", amplamente ilustrado com cerca de 120 imagens autênticas recuperadas, coloridas e em preto e branco, das quais Barthes se "alimentou" para a escrita mensal de suas mitologias. 
O ponto de partida dessa reflexão era, o mais das vezes, um sentimento de impaciência frente ao "natural" com que a imprensa, a arte, o senso comum mascaram continuamente uma realidade que, pelo fato de ser aquela em que vivemos não deixa de ser por isso perfeitamente histórica.

Oferece-nos assim um modelo de desmontagem das operações discursivas que revela que os meios da comunicação de massa naturalizam a linguagem, fazendo as palavras passarem pelas coisas, escondendo dessa maneira as suas verdadeiras intenções. Sem deixar de ser nem de longe um belo exercício da visão, construindo um leitor mais sensível, que consegue perceber o seu entorno para além das aparências (ibidem, 2006b).

Não se trata aí simplesmente de uma coletânea de textos. Barthes toma o cuidado de triar o material e, sobretudo, de produzir, posteriormente, um posfácio intitulado O mito, hoje. Esse posfácio resume e justifica o reagrupamento de textos, sistematizando os materiais, quase sempre bastante variados uns dos outros (um artigo de jornal, uma fotografia de uma revista, um espetáculo, uma exposição), que compõem a obra. É nesse ensaio que de fato encontramos, claramente, o que Barthes (ibidem, p. 199) entende por mito. Ele nos entrega uma definição disso já nas primeiras linhas deste texto: "O que é o mito hoje? Darei de saída uma primeira resposta muito simples, que corresponde perfeitamente à etimologia: o mito é uma fala".

Como segue ainda nos lembrando o próprio Barthes (ibidem), não consiste numa "fala qualquer. São necessárias condições especiais para que a linguagem se transforme em mito" (2006b, p. 199). Portanto, o mito é "um sistema de comunicação, uma mensagem [...] uma forma de significação, que se define pela maneira como se fala" (ibidem, p. 199). Para exemplificar, apoiemo-nos numa das primeiras exemplificações do próprio semiólogo. Uma árvore é uma árvore, mas uma árvore falada por Minou Drout "já não é exatamente uma árvore, é uma árvore decorada, adaptada a um certo consumo, investida de complacência literária, de revoltas, de imagens, em suma, de uso social que se acrescenta à pura matéria" (ibidem, p. 200), observa aí o semiólogo.

Em termos linguísticos, o mito barthesiano pode ser bem explicado a partir do par opositivo central para Saussure, aquele de língua/fala. Sabemos, pela tradição saussuriana, que a língua é convenção e a fala, por sua vez, é o ato individual de seleção e atualização. ${ }^{5} \mathrm{O}$ mito barthesiano consiste numa "dobra", num giro em falso, isto é, problematiza o uso social e histórico que os falantes da língua são capazes de fazer, de tal maneira que os objetos e as matérias passam a significar uma outra coisa para além de uma nomenclatura do mundo. Ocorre aí, como prefere ler Lucia Santaella

5 Note-se que, para Roland Barthes, a língua é o objeto onde está inscrito, desde toda a eternidade humana, o poder. No entanto, a inserção do poder nessa instância não pode ser atentamente observada, visto que os falantes, usuários da língua, esquecem-se de que toda ela é classificação e que toda classificação é opressiva. A linguagem é uma legislação e a língua é o seu código. Nas palavras do semiólogo: "a língua implica uma relação fatal de alienação. Falar, e com maior razão discorrer, não é comunicar, como se repete com demasiada frequência, é sujeitar [...] Mas a língua, como desempenho de toda a linguagem, não é nem reacionária, nem progressista; ela é simplesmente: fascista; pois o fascismo não é impedir de dizer, é obrigar a dizer" (BARTHES, 1980, p. 13-14). 
(2007, p. 20), uma "ultrasignificação", isto é, a amplificação de um sistema primeiro. Logo, não se opera nenhum trabalho de transformação objetiva sobre a linguagem que se "dobra" a fim de significar, mas, como uma espécie de sistema parasita, apenas confere a esse sistema primeiro um outro sentido. Não por acaso, numa resenha intitulada Civilização da imagem, de 1960, publicada na revista Communication, Barthes (2005, p. 68) então nota, "uma linguagem não é o que ela diz, mas o modo como ela diz", advertindo-nos, dessa maneira, que pôr as coisas em seu devido lugar é, antes de tudo, separar a língua da fala.

Ora, o conceito barthesiano de mito evidentemente não se distancia daquele de conotação, esse acréscimo de significado ao signo, formulado pelo linguista dinamarquês formado pelo círculo de Praga e que levou a teoria saussuriana até as últimas consequências, Louis Hjelmslev (2006) ${ }^{6}$, em Prolegômenos a uma teoria da linguagem.

De par com a dicotomia saussuriana, língua/fala, conotação/denotação, ela é um desdobramento e completa a formalização da base saussuriana. É o que nos explica Barthes (2006a) em Elementos de semiologia. A denotação refere-se ao sentido usual ou literal que é dado a uma determinada palavra ou significante, enquanto a conotação é a capacidade que o signo linguístico tem de receber novos significados que acoplam ao seu sentido original em decorrência do seu uso pelos falantes da língua, como se fossem notas, anotações. Daí o termo co-notar, notar duas vezes.

O conceito de conotação indica que é por meio do uso empregado à linguagem que o mito é definido conceitualmente. O conceito de mito impõe ao signo um sentido secundário que é a conotação. Tal ocorrência permitirá a Barthes (2006a) identificar a manifestação formal da ideologia no uso instrumental da língua- afinal, todos sentidos sociais, culturais, históricos, políticos, religiosos, psicológicos que o signo arrasta, quando é atualizado na fala - e assim efetivar a passagem da crítica ideológica à crítica semiológica, sem que, com isso, o viés político se apague ou impregne o fundo de suas análises.

Vejamos mais de perto, nos próprios termos barthesianos, a definição de mito. O mito desloca um signo de seu contexto e o faz funcionar como significante afetado de outro significado, num outro contexto, em que assume uma outra significação de "segundo grau". Há, no mito, escreve Barthes (2006b, p. 206), dois sistemas semiológicos:

[...] um deles deslocado em relação ao outro: um sistema linguístico, a língua (ou os modos de representação que lhe são assimilados), que eu chamaria linguagemobjeto, porque é a linguagem de que o mito se apodera para construir seu próprio sistema; e o mito propriamente dito, que eu chamaria metalinguagem, porque é uma segunda língua, na qual se fala a primeira.

6 Sabe-se que os trabalhos do linguista Louis Hjelmslev não são citados, diretamente, na redação do posfácio "O mito, hoje"; a referência clara a ele só será dada em seu trabalho posterior, em 1964, com a publicação de Elementos de semiologia, uma compilação dos conceitos transmitidos da linguística à semiologia, que foram, inicialmente, apresentados, no seminário de 1962-1963, na École Pratique des Hautes Études 
Tendo percorrido um pouco mais de meio século da primeira edição de Mitologias, parece-nos que temos que concordar com Motta (2004, p. 26), que não deixa de ressaltar a atualidade vigorante desse livro barthesiano, "hoje um clássico [...] cujos ensinamentos ainda não conseguimos trocar por coisa melhor". ?

Podemos, enfim, jogar com a hipótese de que as formulações semiológicas do mito permitem, ainda nos dias de hoje, ser aplicadas aos estudos midiáticos como também aos seus produtos, que fora falar, são todo tempo também falados pelas mídias.

Estamos mais preparados para ver na prática as operações de desmontagem feitas por Roland Barthes (2006b). Dentre os inúmeros ensaios que compõem Mitologias, pinçamos dois deles: "A Grande família dos homens" e "Fotos-choque", nos quais o semiólogo reflete sobre fotos de duas exposições ocorridas em Paris em algum momento dos anos de 1950. Esses fragmentos de Mitologias permitirão, como se verá, fazer a aproximação com a noção de studium de outra obra barthesiana, A câmara clara. Acompanhamos o percurso do pensamento do próprio texto do autor.

Em "A Grande Família dos Homens", o semiólogo escreve sobre sua visita a uma exposição de fotografia vinda dos Estados Unidos, intitulada The Family of Man. O objetivo da exposição, nas palavras de Barthes (2006b, p. 175), era o de "mostrar a universalidade dos gestos humanos na vida cotidiana de todos os homens de todos os países do mundo: nascimento, morte, trabalho, saber, jogo impõem por toda parte os mesmos comportamentos". A exposição buscava demonstrar por meio das imagens fotográficas que existe uma "grande família dos Homens" e representar o homem pela ótica do comunitário, de uma "comunidade humana" fraterna, como salienta Barthes (ibidem, 2006b).

E esse é o próprio "mito", ou a própria "mitologia", tal como ele os definiu (ibidem, 2006b). Sabemos que, de fato, na prática, não existe essa fraternidade. Só se pode passar realmente à ideia de uma verdadeira "família dos Homens" quando o mitólogo - neste caso, o fotógrafo - opera através de duas manobras distintas e complementares para camuflar essa realidade. Essas manobras são: ver tudo como universal, o que serve para renegar as particularidades; e ver tudo como natural, o que serve para afugentar o que, ao invés de ser natural, é cultural.

Barthes (ibidem, 2006b) se apressa a nos fazer observar que as fotografias expostas não nos dizem nada de realmente sério a respeito desses homens supostamente iguais que expõem. Dada a supressão, justamente, do caráter histórico, o que fica é algo vago, vazio; logo, uma ilusão. Trata-se aí de um mundo de sentimentalidades baratas.

Não estamos distantes do que, tempo mais tarde, em A câmara clara, Barthes denominaria de studium. São imagens que, por serem completamente preenchidas de sentimentalidades e moralismo, por muito falam sem nada dizerem. São fotos que não emocionam, ao contrário, anestesiam. Quem as vemos, já as recebemos comentadas pelo fotógrafo,

7 Trabalhando numa esteira sociológica de desmontagem de crítica da cultura e das mídias na contemporaneidade, não podemos deixar de mencionar os estudos do sociólogo francês Michel Mafessoli (2008) em seu lconologies, nos idolotries postmodernes, que, como alude o título, rastreia as iconologias e idolatrias pós-modernas. 
arrematadas pela sua intencionalidade. "Assim, receio que a justificação final de todo esse academicismo seja dar à imobilidade do mundo a segurança de uma 'sabedoria', de uma 'lírica' que só eternizam os gestos do homem para melhor tolhê-lo". (ibidem, 2006b, 178). Voltaremos a essas nomenclaturas barthesianas com mais vagar; por ora, isso já demonstra a pertinência da aproximação que estamos propondo neste estudo.

Já em "Fotos-choque", podemos encontrar mais bem expostas as primeiras críticas de Barthes à imagem fotográfica. Nesse outro ensaio, podemos observar, com maior clareza, a pertinência de aproximação do conceito de mito com os outros dois operadores também barthesianos - extraídos estes de A câmara clara -, a saber: studium e punctum.

Ressaltamos, antes de detalhar esse segundo ensaio, que essas anotações revelam uma coerência de Barthes consigo mesmo e com seu olhar crítico e semiológico. O que muda nesse arco de tempo entre uma obra e outra é o termo que ele utiliza para batizar aquilo que seus olhos analíticos buscam apreender, ora mito, ora studium; mas ambos referem-se a toda uma gama de intencionalidade tanto do mitólogo como do fotógrafo ou fotógrafo-mitólogo que impregna a mensagem fotográfica.

O que de fato quer nos fazer ver Barthes nesse fragmento "Fotos-choque"? Detem-se aí a crítica a uma outra exposição, realizada na galeria do museu Orsay. Dessa vez, ele afirma categoricamente que, nessa exposição, pouco há de fotos que seriam capazes de nos chocar realmente. Para ele, as fotos expostas não têm nada de chocante, é o olhar de quem as vê que lhes dá a qualidade, que não Ihes pertence a priori (BARTHES, 2006b).

Aqui, outra vez, o mitólogo - o fotógrafo - entrega-se a um lirismo barato, na medida em que parece querer capturar e abranger todo o sofrimento que descreve, e assim não resta ao olhar do observador senão patinar sobre aquela superfície de sentimentalidade

exagerada. É por isso que essas fotos são tão "estudiosas", falam demais do tema, não permitem ao leitor ter qualquer tipo de emoção frente a elas. Na expressão de Barthes (ibidem, 2006b, p. 107), são como "comida sintética", ou seja, o criador, em um movimento em vão, tenta enquadrar todo horror do ocorrido que parece não haver mais nada o que fazer com elas e sobre elas, senão olhar sem o mínimo de choque. Para falarmos ainda com Barthes (ibidem, 2006b, p. 107), podemos citar que:

[...] perante elas [fotos] ficamos despossuídos da nossa capacidade de julgamento: alguém tremeu por nós, refletiu por nós, julgou por nós, o fotógrafo não nos deixou nada - a não ser a possibilidade de uma aprovação intelectual: só estamos ligados a essas imagens por um interesse técnico.

\section{De A câmara clara}

Passemos para uma apresentação da derradeira obra em vida de Roland Barthes, publicada, em 1980, A câmara clara, cujo subtítulo é Nota sobre fotografia. Um livro que, se fosse necessário resumir numa palavra, seria um poema. 
Apesar da alusão evidente à fotografia desde o título e o subtítulo, quando rememora esse ancestral da câmara escura que originará posteriormente a caixa preta do aparelho fotográfico, a câmara clara, que consiste num processo bastante simples e rudimentar de fabricação de imagem, por meio de um processo ótico que obtém a imagem por cópia direta, o leitor depara-se aí com um "canto" de poetização extrema. ${ }^{8}$ Isso visava - assinala Marty (2009, p. 105) - "a reconciliar a modernidade e a morte, forçar a modernidade a abandonar o seu horizonte natural, o do aqui e agora, e forçá-la a mergulhar no abismo, nas trevas mais profundas da morte" ${ }^{\prime 9}$. Como nos conta Calvet (1993, p. 259), esse livro é uma promessa de Barthes aos Cahiers du Cinéma, em redigir um "breve texto sobre fotografia", para a coleção de livros que a revista acabava de criar. É o que faz Roland Barthes entre 15 de abril a 3 julho de 1979.

Significativamente subintitulada "nota" (no sentido musical do termo) por não haver, a princípio - como confessa o autor em Do gosto ao êxtase (BARTHES, 1980) -, o desejo de ser uma "enciclopédia". Barthes (2004a, p. 491) pretendia simplesmente desenvolver, nesse livro, uma proposição em relação à fotografia, que passa "à margem do campo científico em questão", e também por ser, o próprio livro, uma obra breve.

Estilhaçado em fulgurantes fragmentos, A câmara clara estrutura-se, na verdade, a partir de quarenta e oito breves textos, divididos em duas partes de 24 cada, como se de dois rolos fílmicos se constituísse. E, numa simetria quase perfeita, inseriu também 24 fotografias, sendo 15 delas na primeira parte e nove na segunda.

Quem alguma vez já se deixou enredar pela trama do texto desse livro sabe que a incursão de Barthes (1984, p. 12), dessa vez em torno da fotografia, se deu com a busca "de um desejo 'ontológico': eu queria saber a qualquer preço o que ela era 'em $\mathrm{si}^{\prime \prime}$ ". Uma meditação fotográfica que se intensifica com a morte de sua mãe, Henriette Barthes, como testemunha Calvet (1993, p. 249): "sozinho no apartamento, Barthes mergulha em profunda melancolia e fica contemplando as fotografias da mãe, observação que dará origem ao livro". ${ }^{10}$

Esse mergulho na linguagem fotográfica, pouco a pouco, permitiu a Barthes (1984) estabelecer dois conceitos que norteariam seu olhar semiótico sobre a imagem. São eles: o studium e punctum. Passemos a definir esses conceitos. O termo studium vem do verbo studare,

8 Noticia-nos Philipe Dubois (2004) em O fotográfico que a câmara clara foi inventada em 1807 por William Hyde Wollaston. Tal invento, em certa medida, não deixa de funcionar como a câmara escura, partindo de uma mesma lógica indiciária.

9 Trato dessa questão no meu livro Roland Barthes e a revelação profana da fotografia, EDUC/FAPESP, 2015.

10 Henriette Binger Barthes morre aos 84 anos em 25 de setembro de 1977. Esse acontecimento foi desconcertante para Roland Barthes. Desde então, ele se torna um de seus temas mais recorrentes, surgindo até mesmo em meio aos cursos no Collège de France. Como mostra este trecho do belo livro O Neutro: “Entre o momento em que decidi o objeto deste curso [...] e o momento em que precisei prepará-lo, ocorreu em minha vida [...] um acontecimento grave, um luto: o indivíduo que vai falar do Neutro já não é o mesmo que decidiu falar dele [...]." (BARTHES, 2003, p. 32). Sabe-se que uma fotografia, aquela que ele intitula de "Jardim de Inverno", datada de 1898, em que se configura Henriette, na ocasião com cinco anos de idade, ao lado de seu irmão com sete, no jardim de inverno da casa Chennevières-sur-Marne, torna-se o centro do qual irradia toda pungência das suas reflexões sobre a imagem fotográfica. 
que é um estudo do mundo: tudo aquilo que não tem pungência, enquanto o punctum vem do verbo latino pungere, "picar", "furar", "perfurar". Conotativamente, aquilo que é pungente, que corta, fere, sensibiliza, alfineta e amortiza. Como se sabe, quando o autor faz tal classificação, ele não fecha as imagens exclusivamente em uma única casa (studium ( punctum): é possível encontrar os dois numa mesma foto, cabendo aos olhos enxergá-los.

O studium é a fotografia que vem informar e comunicar ao sujeito observador (espectador) - a fotografia como um campo de estudo - aquilo que se apresenta naturalmente ao espírito. Torna a fotografia um verdadeiro terreno do saber e da cultura. (ibidem, 1984)

O conceito de punctum advém da própria imagem, tornando-a transparente ao olhar. Refere-se, como isso, a algo que cala e que fascina o corpo; é o campo do indizível da imagem: aquilo que cala na alma do observador, porque o olhar não é capaz de capturar. Ele somente patina sobre essa superfície, pois o punctum apresenta-se no campo cego da imagem. Não é mais o intelecto que responde, mas o corpo que reage àquilo que lhe é apresentado. "Como espectador, eu só me interessava pela Fotografia por 'sentimento'; eu queria aprofundá-la, não como uma questão (um tema), mas como uma ferida: vejo, sinto, portanto, noto, olho e penso" (ibidem, 1984, p.42).

Enfim, poderíamos sintetizar esse par dicotômico da seguinte maneira. O studium refere-se, portanto, a "aplicação a uma coisa, o gosto por alguém, uma espécie de investimento geral, ardoroso, é verdade, mas sem acuidade particular. É pelo studium que me interesso por muitas fotografias, quer as receba como testemunho político, quer as aprecie como bons quadros históricos" (ibidem, 1984, p.45). E o punctum é "esse acaso que me punge (mas também me mortifica, me fere)" (ibidem, 1984, p.46).

Ousaríamos dizer, acompanhando todo o percurso de pensamento de Barthes (1984, p. 75) em A câmara clara, que tanto studium quanto punctum são um detalhe e o que os diferencia é que "certos detalhes poderiam me 'ferir'. Se não o fazem é sem dúvida porque foram colocados lá intencionalmente pelo fotógrafo", termina por notar Barthes (ibidem, 1984, p. 75), contrapondo duas fotos. Uma é a foto de Koen Wessing intitulada "O exército patrulha as ruas" (Nicarágua, 1979), em que, num primeiro plano, se vê soldados patrulhando as ruas e, ao fundo, as freiras que passam. A outra é de Bruce Gilden, sem título (New Orleans, 1973), em que se vê uma religiosa e, ao lado, alguns travestis. Essas fotos levam Barthes (ibidem, p. 76) a escrever: "O contraste despojado (para não dizer: apoiado) não fabrica em mim algum efeito (a não ser, até mesmo, de incômodo)".

O detalhe que estaria mais próximo da ordem do punctum seria aquele que "não é, ou pelo menos não é rigorosamente, intencional, e provavelmente não é preciso que seja; ele se encontra no campo da coisa fotografada como um suplemento ao mesmo tempo inevitável e gracioso", indica Barthes (ibidem, p. 76) no fragmento vinte. Torna-se inevitável não citarmos aquela bela foto de Lewis Hine intitulada "Anormais em uma instituição" (New Jersey, 1924). O que salta do quadrante fotográfico e vem perturbar o olhar - conclui Roland Barthes (ibidem, p. 78) - não são as "cabeças monstruosas e os perfis deploráveis", mas "a imensa gola Danton do garoto" e o "curativo no dedo da menina". 
Arrematemos um pouco as coisas. Se é bem verdade, como já vínhamos vendo desde a apresentação do Mitologias, que o "mito" se dirigia à carga intencional das mensagens depositada pelo fotógrafo em suas imagens, oferecendo ao espectador o significado no lugar do significante, parece-nos que tudo isso, de certa maneira, se converge na noção de studium, possibilitando então dizer que, se o salto do mito ao studium se faz naturalmente, é porque, em larga medida, o studium, diferentemente do punctum, é "estudado" para comover. Escreve Barthes (1984, p. 48): "reconhecer o studium é fatalmente encontrar as intenções do fotógrafo, entrar em harmonia com elas, aprová-las, desaprová-las, mas sempre compreendê-las, discuti-las em mim mesmo". Mais adiante, segue notando ainda o crítico-semiólogo: "isso ocorre um pouco como se eu tivesse de ler na Fotografia os mitos dos Fotógrafos, fraternizando com eles, sem acreditar inteiramente neles. Esses mitos visam evidentemente (é para isso que servem o mito) a reconciliar a Fotografia e a sociedade" (ibidem, p. 48).

Estamos certos de que reconhecer o studium numa foto é, no limite, também ler os "mitos" do fotógrafo, tanto é que, debruçado sobre algumas fotos que são da ordem do studium, Barthes (ibidem, p. 67) pondera se essas imagens podem" 'gritar', não ferir". Nelas, o olho do semiólogo e caçador de mitos reencontra aquilo que, redigindo o fragmento de Mitologias intitulado "Fotos-choque", ele nomeou de "choque fotográfico", que, aliás - cabe dizer -, não tem nada a ver com punctum. Diferente do punctum, o choque "consiste menos em traumatizar do que em revelar aquilo que estava oculto [...] toda uma gama de 'surpresas' (assim são elas para mim, Spectator, mas para o fotógrafo são 'desempenhos')".(ibidem, p. 54-55).

Assim sendo, é o próprio Barthes quem nos entrega no fragmento quatorze todo um dossiê de bizarrices fotográficas que parecem querer somente testemunhar sobre o desempenho do fotógrafo: a raridade, o gosto de certos fotógrafos em registar deformações e monstruosidades do mundo. A imobilização da cena em seu instante decisivo, quando o fotógrafo registra um gesto no ponto de sua trajetória que o olho não conseguiria fazer. A proeza que atesta a manobra do fotógrafo para capturar, por exemplo, uma gota de leite num milésimo de segundo de sua queda. Ou, então, toda uma gama de modificações que a técnica permite fabricar sobre a imagem: sobreimpressão, anamorfoses e, até mesmo, explorações voluntárias de certos "defeitos" (enquadramento, desfoque e todo o tipo de perturbações na perspectiva). Enfim, Barthes (ibidem, p. 56) não suporta essa "espécie de humor na fotografia", de que se utilizam alguns fotógrafos. Isso o leva a escrever: "Todas essas surpresas obedecem a um princípio de desafio (aquilo por que elas me são estranhas): o fotógrafo, como um acrobata, deve desafiar as leis do provável ou mesmo do possível" (ibidem, p. 56-57) 
O autor, por fim, explica, como que resumindo grosseiramente a história da fotografia em dois tempos: o primeiro ocorreu quando se "fotografava o notável" para surpreender e o segundo aconteceu quando se "decreta notável" aquilo que se fotografa (ibidem, p. 57). ${ }^{11}$

\section{O olho de Barthes}

Tudo isso permite-nos dizer - para irmos, de algum modo, já concluindo -, que toda essa incursão recortando alguns pontos do pensamento barthesiano em torno da imagem torna possível entrever uma estética barthesiana para as imagens. Um desejo estético que "não atesta obrigatoriamente a arte do fotógrafo: ele diz apenas ou que o fotógrafo se encontra lá, ou, de maneira mais simplista ainda, que ele não podia não fotografar o objeto parcial ao mesmo tempo que o objeto total", como delineia o próprio Barthes (1984, p. 76)

A noção de punctum de par como aquelas de studium e mito lança, a nosso ver, uma crítica sobre o mundo das imagens que vai ao encontro daquela mesma que Barthes elaborou para a literatura em O grau zero da escritura. Aliás, é o próprio crítico que nos permite inferir uma noção à outra, quando escreve na introdução de Mitologias:

ao ocupar-me dos fatos aparentemente mais afastados de qualquer literatura (um combate de catch, um prato de cozinha, uma exposição de plásticos), não pensava sair de uma semiologia geral do nosso mundo burguês, cuja vertente literária já havia abordado nos meus ensaios precedentes (idem, 2006b, p. 11).

O conceito de "grau zero" alude àquela literatura dita sem estilo, ou melhor ainda, como escreve Barthes (2004b, p. 65-66), "a escritura do grau zero é basicamente uma escritura indicativa ou, se se preferir, amodal [...] a escrita se reduz então a um modo negativo em que as características sociais ou míticas de uma linguagem ficam abolidas em proveito de seu estado neutro e inerte da forma.

O studium é a denúncia barthesiana da fotografia de arte, em que se faz notável e se mostra excessivamente o "desempenho" do fotógrafo, suas intencionalidades. A noção de punctum faz alusão àqueles fotógrafos sem estilo, isto é, aqueles que, por meio de suas imagens, simplesmente, apontam que o fotógrafo esteve lá onde a cena aconteceu e nada mais, sem comentário sobre o acontecimento.

Se, por muito tempo, preferiu-se simplesmente dizer que $A$ câmara clara era o positivo fotográfico do qual o negativo era Mitologias, talvez já seria tempo de lançar uma outra formulação mais justa que seria a seguinte: A câmara clara (1984) é uma versão, total ou puramente fotográfica, de Mitologias (2006b), em que o "segundo grau" da conotação aí intuído desde sempre foi corajosamente levado ao seu "grau zero", cuja versão literária encontramos em seu primeiro livro, O grau zero da escritura (2004b).

11 Note-se, relendo A câmara clara que, tal como existem imagens que estariam mais próximas da ordem do studium e outras do punctum, Barthes entrevê, a nosso ver, também dois fotógrafos. Um seria o "acrobata", que colocaríamos de par com a noção de studium, e o outro, o "agente da morte", aquele que teria mais chance de fabricar imagens que despertam o punctum. 
Vendo a obra barthesiana em perspectiva, é possível delinear aí uma "'Estética da ausência' - o signo vazio, o sujeito vazio, a isenção do sentido" (idem, 2009, p. 62) - para falarmos nos mesmos termos de Susan Sontag (2009) em L'écriture même: à propôs de Barthes - e esse é o ponto em que "o projeto do esteta se autodestrói" e o que se revela é ou o "silêncio" ou a "transformação em outra coisa".

Ora, a estética barthesiana não se respalda na ausência de uma forma, mas busca por uma forma que seja a mais literal possível. Opera-se aí um estado pré-semiológico de "infrasignificação" - para recuperarmos um outro termo proposto por Lucia Santella (2007) -, em que o signo buscaria não atingir o sentido das palavras e, sim, o sentido das próprias coisas. Trata-se, portanto, de uma espécie de gosto barthesiano muito profundo do signo por aquilo que ele pode ter de mais puro. Um significante sem significado.

Em O império dos signos, Roland Barthes (2007) insere uma antecipação disso que vimos ser denominado como punctum. A propósito de uma foto de uma criança japonesa intitulada "Rosto", de Nicolas Bouvier, o semiólogo escreve a legenda com essas palavras, "os olhos e não a alma, a fenda e não o olhar". Os pares opositivos olho/alma; fenda/ olhar opõem a letra à forma, o cerne de uma forma à expressão de um conteúdo patético.

Relembremos, para fecharmos as pontas, uma passagem de Aula, conferência inaugural pronunciada por Barthes, por ocasião de seu ingresso no Collège de France, no momento em que o crítico-professor estava às voltas de sua definição de semiologia. Ouçamos as palavras dele: "Alguém em quem se debateu, nos bons e nos maus momentos, essa diabrura, a linguagem, só pode ser fascinado pelas suas formas de vazio - que são o contrário absoluto do seu oco" (idem, 1980, p. 36).

Rodrigo Fontanari é pós-doutorando no Programa de Pósgraduação em Multimeios da Universidade Estadual de Campinas. É pesquisador associado ao Réseau International Roland Barthes, Equipe Barthes do Institut des Textes et Manuscrits do CNRS.

fontanari.rodrigo@yahoo.fr

\section{Referências}

BARTHES, R. Aula. Tradução de Leyla Perrone-Moisés. São Paulo: Cultrix, 1980.

.A câmara clara: nota sobre fotografia. Tradução de Julio Castañon Guimarães. Rio Janeiro: Nova Fronteira, 1984.

. O neutro. Tradução de Ivone Castilho Benedetti. São Paulo: Martins Fontes, 2003.

. O grão da voz. Tradução de Mario Laranjeira. São Paulo: Martins Fontes, 2004a. 
. O grau zero da escritura. Tradução de Mario Laranjeira. São Paulo: Martins Fontes, 2004b. Fontes,2005.

Inéditos volume 3: imagem e moda. Tradução Ivone Castilho Benedetti. São Paulo: Martins Elementos de semiologia. Tradução de Izidoro Blikstein, São Paulo: Cultrix, 2006 a. Difel, $2006 \mathrm{~b}$

Mitologias. Tradução de Rita Buongermino; Pedro de Souza e Rejane Janowitzer. São Paulo: . O império dos signos. Tradução de Leyla Perrone-Moisés São Paulo: Martins Fontes, 2007. . Sistema da moda. Tradução de Ivone Castilho Benedetti. São Paulo: Martins Fontes, 2009. . Mythologies illustrées. Par Jacqueline Guittard. Paris: Seuil, 2010.

CALVET. L. J. Roland Barthes: uma biografia. São Paulo: Siciliano, 1993.

DUBOIS, P. O ato Fotográfico e outros ensaios. Tradução de Marina Appenzeller. Campinas: Papirus, 1993.

FONTANARI, R. Roland Barthes e a revelação profana da fotografia. São Paulo: EDUC/FAPESP, [2015].

GIL, M. Roland Barthes: au mileu de la vie. Paris: Flammarion, 2012.

HJELMSLEV, L. T. Prolegomenos a uma teoria da linguagem. Tradução J. Teixeira Coelho Netto. São Paulo: Perspectiva, 2006.

MAFESSOLI, M. Iconologies, nos idolotries postmodernes. Paris: Abin Michel, 2008.

MARTY, E. Roland Barthes: o ofício de escrever. Tradução de Daniela Cerdeira. São Paulo: Difel, 2009. MOTTA, L. T. Literatura e contracomunicação. São Paulo: Unimarco, 2004.

. Roland Barthes: uma biografia intelectual. São Paulo: Iluminuras/FAPESP, 2011.

SANTAelLA, L. A cozinha dos sentidos. Folha de São Paulo. Caderno Mais. 23 Dezembro de 2007. SONTAG, S. L'écriture même: à propôs de Barthes. OEuvres Complètes, II. Traduit de l'anglais (ÉtatsUnis) par Philippe Blanchard en collaboration avec l'auteur. Paris: Christian Bourgois éditeur, 2009. 